\title{
CNPY4 inhibits the Hedgehog pathway by modulating membrane sterol lipids
}

Megan Lo ${ }^{\mathrm{a}}$, Amnon Sharir ${ }^{\mathrm{b}}$, Michael D. Paul ${ }^{\mathrm{a}}$, Hayarpi Torosyan ${ }^{\mathrm{a}}$, Christopher Agnew $^{\mathrm{a}}$,

David R. Raleigh $^{\mathrm{c}, \mathrm{d}}$, Natalia Jura ${ }^{\mathrm{a}, \mathrm{e}, 1^{*}}$, Ophir D. Klein ${ }^{\mathrm{b}, \mathrm{f}, 1^{*}}$

${ }^{a}$ Cardiovascular Research Institute, University of California San Francisco, San Francisco, CA 94158, USA

${ }^{\mathrm{b}}$ Program in Craniofacial Biology and Department of Orofacial Sciences, University of California, San Francisco, CA, USA

${ }^{\mathrm{c}}$ Department of Radiation Oncology, University of California, San Francisco, San Francisco, CA, USA

${ }^{\mathrm{d}}$ Department of Neurological Surgery, University of California, San Francisco, San Francisco, CA, USA

${ }^{\mathrm{e}}$ Department of Cellular and Molecular Pharmacology, University of California San Francisco, San Francisco, CA 94158, USA

${ }^{\mathrm{f}}$ Department of Pediatrics and Institute for Human Genetics, University of California, San Francisco, CA, USA

${ }^{1 *}$ Correspondence should be addressed to N.J. (natalia.jura@ucsf.edu) or O.D.K. (ophir.klein@ucsf.edu) 


\section{Introductory paragraph}

The Hedgehog $(\mathrm{HH})$ pathway is critical for development and adult tissue homeostasis ${ }^{1}$. Aberrant HH signaling can cause congenital malformations, such as digit anomalies and

holoprosencephaly ${ }^{2}$, and other diseases, including cancer ${ }^{3}$. Signal transduction is initiated by HH ligand binding to the Patched 1 (PTCH1) receptor on primary cilia, thereby releasing inhibition of Smoothened (SMO), a HH pathway activator ${ }^{4}$. Although cholesterol and several oxysterol lipids, which are enriched in the ciliary membrane, play a crucial role in $\mathrm{HH}$ activation ${ }^{4,5}$, the molecular mechanisms governing the regulation of these lipid molecules remain unresolved. Here, we identify Canopy 4 (CNPY4), a Saposin-like protein, as a regulator of the HH pathway that controls membrane sterol lipid levels. Cnpy $^{4^{-/}}$embryos exhibit multiple defects consistent with $\mathrm{HH}$ signaling perturbations, most notably changes in digit number. Knockdown of Cnpy4 hyperactivates the HH pathway at the level of SMO in vitro, and elevates membrane levels of accessible sterol lipids such as cholesterol, an endogenous ligand involved in SMO activation ${ }^{6}$. Thus, our data demonstrate that CNPY4 is a negative regulator that fine-tunes the initial steps of $\mathrm{HH}$ signal transduction, revealing a previously undescribed facet of $\mathrm{HH}$ pathway regulation that operates through control of membrane composition. 


\section{Main body}

The hedgehog $(H H)$ gene was first identified in Drosophila as a regulator of larval segmentation $^{7}$, after which three mammalian homologs were discovered: desert hedgehog $(D h h)$, Indian hedgehog $(I h h)$, and sonic hedgehog $(S h h)^{8-11}$. Shh is the most widely expressed HH ligand and is found in the epithelium and at epithelial-mesenchymal boundaries of various tissues, including the tooth, gut, lung, and limb, where it controls morphogenesis and adult homeostasis $^{12}$. Precise regulation of $S h h$ signaling is therefore critical for proper tissue development and patterning. Perturbations to the pathway have been linked to severe congenital abnormalities, including polydactyly and holoprosencephaly ${ }^{12}$. Misregulation of Shh pathway genes can also lead to cancers such as basal cell carcinoma, the most common cancer in the United States, and medulloblastoma, the most common malignant brain cancer in children ${ }^{2,3}$.

$\mathrm{HH}$ signal transduction in vertebrates occurs through a tightly regulated process at the primary cilium, an antenna-like organelle that protrudes from the surface of most cells ${ }^{13,14}$. Signaling is initiated by binding of a secreted HH ligand to the PTCH1 receptor, which resides in and at the base of primary cilia ${ }^{15-19}$. HH binding to PTCH1 releases inhibition of the G-protein coupled receptor SMO, leading to SMO accumulation in cilia ${ }^{20}$. There, SMO is likely activated by one or more sterol lipid ligands ${ }^{21}$, whose exact identities remain to be unequivocally determined $^{22}$. Activation of SMO releases the inhibition of the glioma-associated oncogene (GLI) transcription factors (GLI1, 2, and 3) by a negative regulator of the pathway, Suppressor of Fused (SUFU) ${ }^{23}$. This allows the GLI proteins to translocate into the nucleus and initiate transcription of key developmental genes ${ }^{24-26}$. HH activation also upregulates transcription of pathway genes including Ptchl and Glil, leading to a complex signaling feedback loop ${ }^{27,28}$. Additionally, several components of the HH pathway interact with sterol lipids, and both 
depletion of cellular lipids and inhibition of sterol biosynthesis hinders $\mathrm{HH}$ signal transduction ${ }^{29-}$

35. These lipid molecules are thought to influence trafficking of proteins into and out of, and thereby signal transduction from, the cilia ${ }^{5}$. Thus, sterol localization and concentration at the plasma membrane is critically tied to $\mathrm{HH}$ signaling.

We set out to explore the potential role of the Canopy (CNPY) subfamily of saposin and saposin-like (SAPLIP) proteins in the regulation of HH signaling. A number of SAPLIP proteins interact with lipids to modulate processes such as membrane binding, permeabilization, and lipid metabolism. In zebrafish, cnpyl was reported to regulate the development of Kupffer's vesicle, which controls left-right asymmetry through $\mathrm{HH}$ signaling in zebrafish ${ }^{36-38}$; however, the interaction of cnpyl with $\mathrm{HH}$ signaling was not explored. In humans and mice, Cnpyl appears truncated, and Cnpy2 and Cnpy3 knockout mice do not display visible alterations of $\mathrm{HH}$ pathway $^{36,39-41}$. We therefore turned to the remaining family member, Cnpy4, to study whether it may play a role in $\mathrm{HH}$ signaling. We bred Cnpy4 knockout mouse lines and assessed the effect of CNPY4 loss of function in mutant embryos (Fig. 1; Extended Data Fig. 1). Of the Cnpy $4^{-/-}$ embryos examined, $85 \%$ exhibited abnormalities in hindlimb digit number, ranging from the formation of one or two supernumerary digits on the anterior side of the limb (termed preaxial polydactyly) to a loss of up to three posterior digits (Fig. 1c, Extended Data Fig. 1a, b). Similar bi-directional phenotypic changes to the limb buds have also been observed in patients with loss of function Gli3 mutations ${ }^{42,43}$. Approximately $20 \%$ of the $C n p y 4^{-/-}$mutants exhibited other anomalies consistent with $\mathrm{HH}$ pathway misregulation, including rostral and/or caudal neural tube closure defects, splayed vertebrae, and abnormal rib morphology with fusions and bifurcations $^{44,45}$ (Extended Data Fig. 1c). Due to the high penetrance of the limb phenotype and 
the central role of Shh in controlling digit number, we focused further analysis on limb abnormalities in Cnpy4 knockout mice.

To explore whether Cnpy4 modulates $S h h$, we first examined the expression of $S h h$ and its downstream effector Gli1 during limb development in mutant embryos. Shh and Gli1 expression expanded anteriorly in the early hindlimb buds of Cnpy4 mutants (embryonic day (E) 10.5 - E11.5), and ectopic expression of Shh and Glil was present in anterior domains at later developmental stages (E12.5) (Fig. 2a), in line with misactivation of the HH pathway. These changes are consistent with those observed in other human patients and mouse models with preaxial polydactyly ${ }^{46-48}$. In a small number of mutants, reduction of Shh and Glil expression was observed (Extended Data Fig. 2), paralleling the minority of Cnpy $4^{-/-}$mutants manifesting oligodactyly.

In order to measure the Cnpy4-dependent changes in HH signaling at the cellular level, we utilized a luciferase reporter assay to measure Gli expression in NIH3T3 cells following transient Cnpy4 knockdown with siRNA (Extended Data Fig. 3a). Consistent with the predominant polydactyly phenotype and other developmental abnormalities we observed in Cnpy4 knockout embryos, silencing of Cnpy4 resulted in elevated basal activation of the $\mathrm{HH}$ transcriptional program and potentiated signaling in response to $\mathrm{HH}$ pathway agonists (Fig. 2b, c). These effects were independent of the ligand used to activate the pathway, including a chemical SMO agonist (SAG), recombinant SHH, and both synthetic (20(S)-hydroxycholesterol) and cilia-associated (24(S), 25-epoxycholesterol) oxysterols that bind and activate $\mathrm{SMO}^{44}$. To corroborate these results, we directly analyzed Gli1 transcript levels in NIH3T3 cells using qRTPCR. In line with the results from the HH luciferase reporter assay, we found that Glil expression was greatly increased in Cnpy4 knockdown cells compared to those treated with 
control siRNA upon ligand stimulation (Fig. 2d, e; Extended Data Fig. 3b, c). Thus, the HH pathway is hyperactive in cells lacking Cnpy4, suggesting that CNPY4 is a negative regulator of the HH pathway.

Morphological differences in cilia, changes in cell ciliation, and improper trafficking of ciliary proteins are all linked to aberrant $\mathrm{HH}$ activity during development ${ }^{5,13,14,49-51}$. We therefore asked if ciliary defects could explain the hyperactivation of the $\mathrm{HH}$ pathway observed by staining for acetylated tubulin, a marker of the ciliary axoneme, in Cnpy4 deficient NIH3T3 cells and in mouse embryonic fibroblasts (MEFs) derived from $C n p y 4^{-/}$embryonic limb buds (Fig. 3a; Extended Data Fig. 4a-c). NIH3T3 cells with Cnpy4 knockdown and Cnpy $4^{-/}$MEFs did not show significant differences in the percentage of ciliated cells compared to control cells (Fig. 3b; Extended Data Fig. 4d). Furthermore, the length and overall morphology of cilia were not visibly altered by depletion of CNPY4 (Fig. 3a, c; Extended Data Fig. 4c, e). The intensity of SMO staining in the cilia upon SAG stimulation was also unchanged in Cnpy4 silenced cells, indicating that the ability of SMO to traffic into the cilia was not impaired (Extended Data Fig. 4f, g). Similar uncoupling of ciliary morphology and SMO trafficking from $\mathrm{HH}$ activation were recently reported upon ablation of the cholesterol biosynthesis enzyme DHCR7 $7^{52}$. Thus, we concluded that the effect CNPY4 exerts on the HH pathway was likely through signalingspecific events, rather than ciliary or protein compartmentalization abnormalities.

To map the impact CNPY4 exerts on HH signal transduction components, we utilized our in vitro system to perform epistasis experiments. Although knockout of Ptch1 alone constitutively activates the $\mathrm{HH}$ pathway ${ }^{20}$, knockdown of Cnpy4 further activated the $\mathrm{HH}$ transcriptional program in Ptchl $^{-/-}$MEFs compared to control cells (Fig. 3d; Extended Data Fig. 5a-c), suggesting CNPY4 intersects the HH pathway parallel to or downstream of PTCH1. 
Knockout of Sufu, a negative regulator of the pathway downstream of PTCH1, also results in constitutive activation of the HH pathway ${ }^{53}$ (Fig. 3e; Extended Data Fig. 5d-f). However, in contrast to the effect of Cnpy4 knockdown in Ptch1 ${ }^{-/-}$MEFs, knockdown of Cnpy4 in Sufu ${ }^{-/-}$ MEFs resulted in a comparatively modest increase of Gli1 mRNA transcription, suggesting CNPY4 functions upstream of SUFU to inhibit HH signal transduction.

SMO functions downstream from PTCH1 and upstream from SUFU ${ }^{9}$. Since $\mathrm{Smo}^{-/} \mathrm{MEFs}$ are unable to transduce $\mathrm{HH}$ signals in response to pathway ligands, we examined whether the observed CNPY4-mediated modulation of HH signaling required SMO using both genetic (Fig. 3f, g; Extended Data Fig. 6a, b) and pharmacological (Fig. 3h, i; Extended Data Fig. 6c-e) perturbations. Remarkably, in the absence of SMO, SAG or recombinant SHH stimulation was unable to elicit hyperactive HH signaling after Cnpy4 knockdown (Fig. 3f, g; Extended Data Fig. 6b), indicating that, like PTCH1, CNPY4 modulates HH activity through SMO. This lack of hyperactivation was also observed in Cnpy4-silenced NIH3T3 cells when SMO was pharmacologically inhibited by its antagonist SANT-1, which directly competes with SAG for binding to SMO (Fig. 3h, i; Extended Data Fig. 6d). We noted that these cells displayed slightly elevated levels of basal HH activity upon knockdown of Cnpy4, despite the absence or repression of SMO in these cells (Fig. 3f-i; Extended Data Fig. 6b, d), although to a much lesser extent than cells expressing SMO. Together these findings point to an essential role of SMO in the ligand-dependent potentiating effect of CNPY4 loss on HH signaling.

As SMO and PTCH1 are both transmembrane proteins whose signaling is likely sensitive to the local lipid environment, we asked if CNPY4, as a SAPLIP protein, may modulate the lipid composition of the membrane. In comparison to other membrane compartments, the ciliary membrane in which PTCH1 and SMO reside is highly enriched in cholesterol and oxysterols ${ }^{54}$. 
These lipids have been shown to bind and activate $\mathrm{SMO}^{21,55,56}$. We therefore probed the ability of CNPY4 to interact with cholesterol and several of these oxysterol compounds in vitro. We purified a recombinant construct of human CNPY4 (CNPY4 $\triangle \mathrm{Ct})$ lacking its signal sequence and C-terminal tail, which is predicted to be largely unstructured (Extended Data Fig. 7a). Purified CNPY4 $4 \mathrm{Ct}$ is well-folded and predominantly alpha helical, as expected for a SAPLIP protein (Extended Data Fig. 7b). However, under the conditions tested, recombinant CNPY4 $\Delta$ Ct did not appear to bind cholesterol (Extended Data Fig. 7c, d). Furthermore, purified CNPY4 $\Delta \mathrm{Ct}$ did not display measurable binding to a number of oxysterols known to be specifically enriched in the ciliary membrane and directly involved in $\mathrm{HH}$ pathway activation ${ }^{44}$ (Extended Data Fig. 7e). As the ability of many SAPLIP proteins to interact with lipids is directly tied to their dimerization ${ }^{57-}$ ${ }^{61}$, we tested if CNPY4 is a dimer. Size exclusion chromatography of recombinant CNPY $4 \Delta \mathrm{Ct}$ (Extended Data Fig. 7a) and co-immunoprecipitation between two differentially tagged constructs of full-length CNPY4 (Extended Data Fig. 7e, f) are consistent with CNPY4 being a monomer. Thus, CNPY4 likely modulates the lipid membrane beyond direct interaction with its lipid components.

We therefore tested the possibility that the absence of CNPY4 could increase the membrane levels of unbound accessible sterols, among them cholesterol ${ }^{62}$, which is most abundant in animal plasma membranes and was recently proposed to be a ligand responsible for SMO activation ${ }^{6}$. To directly measure the levels of accessible sterols in the plasma membrane of intact cells, we used a modified protein probe derived from the bacterial toxin Perfringolysin $\mathrm{O}$ (PFO*) coupled to a fluorescent tag ${ }^{62}$. Remarkably, NIH3T3 cells in which Cnpy4 was knocked down displayed significantly elevated levels of accessible sterols compared to control treated cells (Fig. 4a, b). Additionally, MEFs derived from embryonic limb buds of Cnpy4 null animals 
had notably increased levels of accessible sterols in a basal state (Fig. 4c). These data indicate that the inhibitory effect of CNPY4 on the HH pathway is likely a consequence of decreased levels of sterol lipids at the plasma membrane.

Taken together, our results reveal a new mechanism by which $\mathrm{HH}$ pathway activation is regulated via CNPY4-dependent control of sterol lipids in the membrane. Our data demonstrate that Cnpy4-dependent alteration of sterol lipid levels in the membrane directly modulate SMOdependent $\mathrm{HH}$ activation. While increasing evidence supports the important role of lipids in signal transduction between PTCH1 and SMO, the molecular mechanisms governing these effects are not fully elucidated ${ }^{29-35,41-45}$. Recent studies have shown that both PTCH1 and SMO have several binding sites for sterols, including cholesterol, and that a subset of these binding events are essential for SMO activation ${ }^{55,56,63-66}$. Current models of $\mathrm{HH}$ activation propose that PTCH1 inhibits SMO by sequestering these activating sterols away from $\mathrm{SMO}^{4,67}$. This is thought to occur indirectly and to involve a proposed function of PTCH1 as a cholesterol pump, resulting in altered lipid composition of the plasma membrane $e^{4,66}$. Our data suggest that, similar in effect to PTCH1, but likely through a distinct, separate mechanism, CNPY4 regulates membrane composition to fine-tune SMO-dependent $\mathrm{HH}$ activation (Figure 4d). Our data also reveal that, by doing so, deletion of Cnpy4 can bypass the PTCH1-inhibition of $\mathrm{HH}$-activation (Figure 4d). Intriguingly, we additionally observed that depletion of Cnpy4 causes a SMOindependent increase in basal $\mathrm{HH}$ activity, suggesting that accessible sterol levels in the membrane may contribute to $\mathrm{HH}$ signal transduction through multiple mechanisms. Recent work has illustrated that SMO movement into the cilia occurs even in the absence of ligand stimulation, albeit at much slower rates likely limited by diffusion ${ }^{68,69}$, and that sterol biosynthesis enzymes may regulate the ability of SMO to accumulate by priming the cilia via 
synthesis of sterols ${ }^{52}$. It is therefore possible that accessible sterol lipids affected by Cnpy4

knockdown may be playing such a role, in addition to acting as a ligand for SMO activation.

How CNPY4 regulates the levels of accessible sterols at the plasma membrane remains an open question. CNPY4, as an ER-resident SAPLIP (Extended Data Fig. 8), is well positioned to assist with the synthesis, maturation, and membrane trafficking of lipids, such as sterols ${ }^{70,71}$. SAPLIP proteins can directly interact with lipids in the membrane in order to extract them for enzymatic presentation or membrane lysis ${ }^{49-51}$, and it possible that full-length CNPY4 maintains this functionality that we could not measure using the recombinant, truncated variant of CNPY4. Alternatively or possibly concurrently, CNPY4 might influence the maturation and membrane trafficking of components of the $\mathrm{HH}$ pathway, such as the SMO receptor. A similar function of CNPY4 was previously reported in the regulation of trafficking of Toll-like receptors ${ }^{72,73}$. Our findings elucidate a new regulatory modality in the HH pathway and identify a previously unknown function of CNPY4 as a regulator of $\mathrm{HH}$ pathway via modulation of plasma membrane sterols accessibility. This work provides a new context for unraveling the cellular mechanisms underlying previously reported functions of other CNPY proteins ${ }^{49-51}$.

\section{MATERIALS AND METHODS}

Mouse breeding. Mice were maintained in the University of California San Francisco (UCSF) specific pathogen-free animal facility in accordance with the guidelines established by the Institutional Animal Care and Use Committee and Laboratory Animal Resource Center. All experimental procedures were approved by the Laboratory Animal Resource Center at UCSF. Mice were maintained in temperature-controlled facilities with access to food and water ad 
libitum. Cnpy4 heterozygote mice were produced by Lexicon (http://www.lexicon-genetics.com).

To generate embryos at specific time points, adult mice were mated overnight, and females were checked for a vaginal plug in the morning. The presence of a vaginal plug was designated E0.5.

Micro-computed tomography. Whole embryo or limb buds were collected and dehydrated through an ethanol series up to $70 \%$ ethanol. Samples were soaked in phosphotungstic acid (1\%) overnight to differentially stain soft tissues as described previously ${ }^{74}$ and scanned using MicroXCT-200 (Carl Zeiss Microscopy) at $60 \mathrm{kV}$ and $200 \mu \mathrm{A}$. We obtained 1200 projection images, taken at a total integration time of 3 seconds with linear magnification of $2 \mathrm{x}$ and a pixel size of $6.4 \mu \mathrm{m}$. The volume was reconstructed using a back projection filtered algorithm (Zeiss, Pleasanton, CA). Following reconstruction, tissues were manually segmented and rendered as 3D surfaces using Avizo (FEI).

Whole-mount in situ hybridization. Digoxygenin-labeled RNA probes (Roche) were generated by in vitro transcription from plasmids containing fragments of murine Shh and Sox9. Samples were fixed in $4 \%$ PFA overnight at $4^{\circ} \mathrm{C}$, and the hybridization was carried out as previously described $^{9}$

RNA-scope in situ hybridization. An RNAscope 2.5 HD Red (ACD, 310036, 322350)

detection kit was used according to the manufacturer's instructions. Sections were boiled in the target retrieval solution at $\sim 100{ }^{\circ} \mathrm{C}$ for $15 \mathrm{~min}$ and incubated in the Protease Plus solution at 40 ${ }^{\circ} \mathrm{C}$ for 15 min. Mus musculus Cnpy4 probe (475121 (lot \# 16182A)) was used.

Whole-mount $l a c Z$ staining. Embryos were fixed for $45 \mathrm{~min}$ in $4 \%$ PFA at $4{ }^{\circ} \mathrm{C}$, washed three times in rinse buffer containing $0.01 \%$ deoxycholate, $0.02 \% \mathrm{NP}-40,2 \mathrm{mM} \mathrm{MgCl}$, and $5 \mathrm{mM}$ 
EGTA at room temperature and stained for $1 \mathrm{hr}$ at $37^{\circ} \mathrm{C}$ in rinse buffer supplemented with 1 $\mathrm{mg} / \mathrm{mL} \mathrm{X}$-gal, $5 \mathrm{mM} \mathrm{K}{ }_{3} \mathrm{Fe}(\mathrm{CN})_{6}$, and $5 \mathrm{mM} \mathrm{K} 4 \mathrm{Fe}(\mathrm{CN})_{6}$.

Cell culture and drug treatments. Cells were cultured in Dulbecco's modified Eagle media (Gibco) supplemented with 10\% FBS (Hyclone) and penicillin streptomycin (Gibco) and incubated at $3^{\circ} 7 \mathrm{C}$ with $5 \% \mathrm{CO}_{2}$. All cells lines were regularly tested for mycoplasma contamination using the MycoAlert mycoplasma detection kit (Lonza). Stimulations were performed in low-serum OptiMEM (Life Technologies) to induce ciliation with $100 \mathrm{nM}$ SAG (EMD Millipore), $1 \mu \mathrm{g} / \mathrm{mL}$ recombinant SHH (R\&D Systems), $30 \mu \mathrm{M}$ 20(S)-hydroxycholesterol (Cayman Chemicals), $30 \mu \mathrm{M}$ 24(S), 25-epoxycholesterol (Avanti Polar Lipids), or $25 \mu \mathrm{M}$ SANT-1 (Selleckchem). Incubations with SAG, SHH, and SANT-1 were done for 24 hours and oxysterols were done for 30-36 hours.

MEF generation. Embryos were isolated and washed in 1x PBS twice. Limb buds were separated using sterile tweezers from each embryo and washed with DMEM before incubation with $0.25 \%$ Trypsin/EDTA (Gibco) at $37^{\circ} \mathrm{C}$ for 10 minutes. Trypsin was quenched by addition of DMEM supplemented with FBS and penicillin streptomycin. Cells were pipetted up and down at least 10 times to further dissociate cells before being transferred into fresh $15 \mathrm{~mL}$ tubes. Cells were gently pelleted at $200 x g$ for 5 minutes at room temperature. Supernatant was carefully aspirated and cells were resuspended in fresh media and plated in 6-cm plates (Gibco). Additional cell debris was aspirated off and fresh media added daily until cells reached confluency, upon which they were split and expanded once before being pooled and flash frozen.

siRNA transfection. 22.5 pmol of siRNA SMARTpool (Dharmacon) were transiently transfected into indicated cells using lipofectamine RNAiMax (Invitrogen) according to the 
manufacturer's protocols. Cells were transfected for 72 hours before cell analysis. Confirmation of mRNA silencing was done by qRT-PCR analysis and confirmation of protein knockdown was performed via Western blotting.

qRT-PCR analysis. Cells were grown in either 6- or 12-well plates and treated with indicated expression conditions. RNA was extracted from cells using the RNEasy Mini kit (Qiagen) and reverse-transcribed to produce cDNA using the iScript cDNA synthesis kit (Bio-Rad). qRT-PCR was performed using Power-Up SYBR Green Master Mix (Applied Biosystems) on an Invitrogen real-time PCR machine. mRNA transcript relative abundances were calculated using the $\Delta \Delta \mathrm{Ct}$ method against Gapdh.

Table 1.1 qRT-PCR primers.

\begin{tabular}{|l|l|l|}
\hline Gene & Forward & Reverse \\
\hline Gapdh (mouse) & tgccccatgtttgtgatg & tgtggtcatgagccettcc \\
\hline Cnpy4 (mouse) & gacaaaagaggaggaagatgacacag & ccaggatccgctcgcacaaattctcc \\
\hline Glil (mouse) & ggtgctgcctatagccagtgtcctc & gtgccaatccggtggagtcagaccc \\
\hline
\end{tabular}

Luciferase-based reporter assays. Cells were plated in 6-well plates and transfected with siRNA as described above at least 16 hours post-plating. $396 \mathrm{ng}$ of Gli1-responsive Firefly luciferase reporter plasmid, 4 ng of a control Renilla luciferase reporter plasmid under the control of a constitutively active TK promoter, and $1 \mu \mathrm{g}$ of pcDNA3.1+ empty vector were transfected into cells at least 6 hours post-siRNA transfection using lipofectamine LTX with Plus reagent (Invitrogen) according to the manufacturer's protocol. 16 hours-post transfection, cells were recovered with fresh media for 24 hours. Stimulation with indicated ligand was performed 
in low-serum OptiMEM media (Gibco) for 24-36 hours. Luciferase assays were conducted using the Dual Luciferase Reporter Assay System (Promega) and measured on a GloMax 96 Microplate Luminometer with Dual Injectors (Promega).

Immunofluorescence staining. NIH3T3 or COS-7 cells were plated onto glass coverslips and transfected the following day. Cells were fixed in 3.7\% PFA solution diluted in 1x PBS at room temperature with rocking and then incubated with a $0.1 \%$ Triton X-100 and $2.5 \%$ BSA solution in 1x PBS to permeabilize cells and to block for non-specific antibody interaction. Primary antibodies were diluted in blocking buffer and incubated overnight at $4{ }^{\circ} \mathrm{C}$ then washed out three times with $0.1 \%$ Triton X-100 in $1 \mathrm{x}$ PBS. Secondary antibodies were diluted in blocking buffer and incubated for 2 hours at root temperatures before subsequent washes. DAPI staining was conducted for 10 minutes following the last wash before cells were mounted onto glass coverslips with Prolong Gold AntiFade Mountant (Life Technologies).

PFO* staining and FACS analysis. Cells were grown in 6-wells and treated with indicated conditions. Cells were lifted with $0.5 \%$ Triton-EDTA and gently pelleted by centrifugation at 200xg for 5 minutes. Pellets were washed gently two times with 1x PBS before incubation in blocking buffer (10 mg/mL BSA in 1x PBS) for 10 minutes on ice. Cells were pelleted once more before incubation with $5 \mu \mathrm{g} / \mathrm{mL}$ PFO* probe diluted in blocking buffer for 30 minutes on ice. Cells were gently washed one time with 1x PBS before analysis by FACS. Fluorescent intensity measurements by flow cytometry were performed on a Sony Cell Sorter SH800 using a $638 \mathrm{~nm}$ laser for excitation. Live and singlet populations were selected based on forward and side scatter. No further gating was used to select cell populations. Outliers were identified using the identify outliers function on Prism 8 (GraphPad). 
Microscopy. Bright-field images were acquired on an Axio Imager.Z2 upright microscope (ZEISS) for whole mount, in situ hybridization and lacZ staining. Immunofluorescence and PFO* images were acquired on either a Nikon Elipse Ti with a CSU-X1 spinning disc confocal and Andor Clara interline CCD camera with a Nikon Plan Apo 60x oil objective or a Zeiss LSM 800 confocal laser scanning microscope with a 63x oil objective. Cell length calculations and SMO intensity analysis was done on Fiji.

Recombinant protein expression and purification. CNPY4 constructs were synthesized by Genscript and subcloned into a pET28b plasmids with a 10xHis tag sequence. Cloning verification was done by DNA sequencing (Elim biotechnology). Constructs were transformed into SHuffle T7 competent $E$. coli cells (NEB) and underwent antibiotic selection on Kanamycin plates for 16 hours at $37^{\circ} \mathrm{C}$. A single colony was used to inoculate a Luria broth starter culture supplemented with appropriate antibiotic for 16 hours at $37^{\circ} \mathrm{C}$ and $220 \mathrm{rpm}$ shaking. $10 \mathrm{~mL}$ of starter culture was used to inoculate $900 \mathrm{~mL}$ of Terrific broth supplemented with appropriate antibiotic and $100 \mathrm{~mL}$ of $10 x$ phosphate buffer $\left(0.17 \mathrm{M} \mathrm{KH}_{2} \mathrm{PO}_{4}, 0.72 \mathrm{M} \mathrm{K}_{2} \mathrm{HPO}_{4}\right)$. Cells were grown at $37^{\circ} \mathrm{C}, 220 \mathrm{rpm}$ shaking to an $\mathrm{OD}_{600}$ of $0.6-0.8$ before being induced with isopropyl $\beta$ D-1-thiogalactopyranoside to a final concentration of $0.5 \mathrm{mM}$. Cultures were grown for an additional 20 hours at $18^{\circ} \mathrm{C}$ and $220 \mathrm{rpm}$ shaking. Cells were collected by centrifugation using an Avanti centrifuge equipped with a JA 8.5 rotor at $4000 x g, 40$ minutes, $4^{\circ} \mathrm{C}$. Pellets were flash frozen for later purification or resuspended in binding buffer (50 mM HEPES, pH 8.0, $500 \mathrm{mM}$ $\mathrm{NaCl}, 20 \mathrm{mM}$ imidazole, $\mathrm{pH}$ 8.0, 5\% glycerol) supplemented with DNaseI (Sigma Aldrich) and cOmplete mini EDTA-free protease inhibitor cocktail (Roche) and lysed via sonication at 30\% amplitude, 4 seconds on, 2 seconds off, for a total of 5 minutes. Lysates were clarified in an Avanti centrifuge equipped with a JLA 25.50 rotor at $20,000 \mathrm{xg}, 40$ minutes, $4^{\circ} \mathrm{C}$. Clarified 
lysates were incubated with Ni-NTA 6 Fast Flow beads (GE Life Sciences), with gentle rotation, for 16 hours at $4{ }^{\circ} \mathrm{C}$ before being applied to a gravity flow Econo-column (Bio-Rad). Beads were washed thoroughly with 20 column volumes of binding buffer followed by 10 column volumes of binding buffer supplemented with an additional $12.5 \mathrm{mM}$ imidazole. The recombinant protien was eluted in 5 column volumes of elution buffer (binding buffer with $250 \mathrm{mM}$ imidazole). The elution was buffer exchanged back into low Imidazole binding buffer and incubated with $1 \mathrm{mg}$ of recombinant $3 \mathrm{C}$ protease for 16 hours at $4{ }^{\circ} \mathrm{C}$. Uncleaved protein was removed by passing over fresh Ni-NTA 6 resin. The protein was then diluted 10 times with mono Q binding buffer (50 mM HEPES, pH 8.0) and applied to a MonoQ 5/50 GL column (GE Life Sciences) connected to an AKTA Pure system (GE Life Sciences).. Recombinant hCNPY4 $\Delta \mathrm{Ct}$ was eluted with a linear gradient of elution buffer (50 mM HEPES, pH 8.0, $500 \mathrm{mM} \mathrm{NaCl})$. Elutions were concentrated using an Amicon Ultra-15 10k MWCO centrifugal filter (Millipore) before being loaded onto a a Supderdex 200 16/600 column (GE Life Sciences) equilibrated in size exclusion chromatography (SEC) buffer (50 mM Bicine, $\mathrm{pH} 9.0,150 \mathrm{mM} \mathrm{NaCl})$. Fractions confirmed to contain pure hCNPY4 $\triangle \mathrm{Ct}$ by SDS-PAGE analysis were pooled and flash-frozen in liquid nitrogen and stored at $-80^{\circ} \mathrm{C}$.

Circular dichroism. Purified CNPY proteins were analyzed on a Jasco J-810 spectropolarimeter at $1 \mathrm{~nm}$ steps. Proteins were analyzed at an approximate concentration of $2 \mu \mathrm{M}$ in a $50 \mathrm{mM}$ sodium phosphate buffer, $\mathrm{pH} 7.0$ at $25^{\circ} \mathrm{C}$. Thermal melt data was collected at $222 \mathrm{~nm}$ with a temperatures range of $25^{\circ} \mathrm{C}$ to $95^{\circ} \mathrm{C}$ in increments of $5^{\circ} \mathrm{C}$. CNPY $4 \Delta \mathrm{Ct}$ was additionally incubated with $30 \mu \mathrm{M}$ of cholesterol, 20(S)-hydroxycholesterol, or 24(S), 25-epoxycholesterol prior to thermal melt analysis for assessment of binding capacity. Data for three, averaged reads was fitted using the $\log ($ agonist) vs. response -- Variable slope non-linear analysis on Prism 8 
(GraphPad), and the LogEC50 from the analysis was reported as the melting temperature. Error bars correspond to calculated standard error of the mean.

Fluorescence polarization. Purified human CNPY4 $\triangle \mathrm{Ct}$ in SEC buffer (50 mM HEPES, pH 8.0, $150 \mathrm{mM} \mathrm{NaCl}$ ) were analyzed for binding to $50 \mathrm{nM}$ BODIPY-cholesterol (Cayman Chemical) at the indicated protein concentrations. $1 \%$ Tween-20 was added to the reaction mixture.

Experiments were performed with a reaction volume of $20 \mu \mathrm{L}$ in triplicate using a black-bottom 384-well plates (Corning) on an Analyst AD plate reader (Molecular Devices). Excitation and emission wavelengths used for the kinetic experiments were $480 \mathrm{~nm}$ and $508 \mathrm{~nm}$, respectively, according to the manufacturer's recommendation. Kinetic reads were performed over 15 minutes with 30 second intervals. As no significant difference was observed, signal was averaged across all time points for each triplicate with standard error calculated for each data point. Data was fitting using the Semilog line -- $\mathrm{X}$ is $\log , \mathrm{Y}$ is linear non-linear analysis on Prism 8 (GraphPad). Error bars correspond to calculated standard error of the mean.

Statistical analysis. All statistical analysis were performed using Prism 8 (GraphPad). Significance analysis for luciferase assay ( $\mathrm{N}=9 ; 3$ biologic replicates and 3 technical replicates) and qRT-PCR ( $\mathrm{N}=12 ; 4$ biologic replicates and 4 technical replicates) analyses were done using the Mann-Whitney non-parametric test. Ciliation $(\mathrm{N}=77$ with $\mathrm{t}=1.785, \mathrm{df}=152$ for NIH3T3 cells; $\mathrm{N}=79$ with $\mathrm{t}=1.855, \mathrm{df}=156$ for MEF cells $)$ and FACS analyses $\left(\mathrm{N}=92183\right.$ for Cnpy $^{+/+}$MEFs and $\mathrm{N}=74848$ for Cnpy $^{-/--}$MEFs with $\mathrm{t}=183.1$ and $\mathrm{df}=95074 ; \mathrm{N}=244550$ for siCtrl NIH3T3 cells and $\mathrm{N}=291375$ for siCnpy4 $\mathrm{NIH} 3 \mathrm{~T} 3$ cells with $\mathrm{t}=295.6, \mathrm{df}=503909$ ) were performed using the Welch's t-test. All statistical analyses were two-tailed. 


\section{ACKNOWLEDGMENTS}

We thank Pao-Tien Chuang and Jeremey Reiter for the NIH3T3, Sufu ${ }^{-/}$, and Ptch1 ${ }^{-/-}$MEF cell lines, Maia Kinnebrew and Rajat Rohatgi for the PFO* probe, Shao-qing Zhang and Haifan Wu for their guidance on CD experiments, Vikas Daggubati for assistance with experimental procedures, and Sarah Findakly-Oshima for help with confocal imaging. We also thank Tom Kornberg, Aashish Manglik, Kara McKinley, and Jennifer Kung for critical reading of the text and members of the Jura and Klein labs for their helpful discussions. This work was funded by the UCSF Program for Breakthrough Biomedical Research and NIDCR R01-DE028496 and R35-DE026602 to O.D.K.

\section{AUTHOR CONTRIBUTIONS}

N.J. and O.D.K. conceived of and initiated the project. M.L. performed the in cell-based experiments, recombinant protein expression and purifcation, and in vitro experiments. A.S. generated the mouse models and performed the in situ hybridizations. M.D.P, H.T., and C.A. assisted with the in vitro experiments. M.L., N.J., and O.D.K. wrote the manuscript with provisions provided by D.R.R.

\section{COMPETING INTERESTS}

The authors declare no competing interests. 


\section{REFERENCES}

1. Lum, L. \& Beachy, P. A. The Hedgehog response network: sensors, switches, and routers. Science 304, 1755-1759 (2004).

2. Nieuwenhuis, E. \& Hui, C. C. Hedgehog signaling and congenital malformations. Clinical Genetics 67, 193-208 (2004).

3. Raleigh, D. R. \& Reiter, J. F. Misactivation of Hedgehog signaling causes inherited and sporadic cancers. J. Clin. Invest. 129, 465-475 (2019).

4. Kong, J. H., Siebold, C. \& Rohatgi, R. Biochemical mechanisms of vertebrate hedgehog signaling. Development 146, (2019).

5. Garcia, G., Raleigh, D. R. \& Reiter, J. F. How the Ciliary Membrane Is Organized InsideOut to Communicate Outside-In. Curr. Biol. 28, R421-R434 (2018).

6. Kinnebrew, M. et al. Cholesterol accessibility at the ciliary membrane controls hedgehog signaling. eLIFE 8, (2019).

7. Nüsslein-Volhard, C. \& Wieschaus, E. Mutations affecting segment number and polarity in Drosophila. Nature 287, 795-801 (1980).

8. Echelard, Y. et al. Sonic hedgehog, a member of a family of putative signaling molecules, is implicated in the regulation of CNS polarity. Cell 75, 1417-1430 (1993).

9. Riddle, R. D., Johnson, R. L., Laufer, E. \& Tabin, C. Sonic hedgehog mediates the polarizing activity of the ZPA. Cell 75, 1401-1416 (1993).

10. Krauss, S., Concordet, J. P. \& Ingham, P. W. A functionally conserved homolog of the Drosophila segment polarity gene hh is expressed in tissues with polarizing activity in zebrafish embryos. Cell 75, 1431-1444 (1993).

11. Roelink, H. et al. Floor plate and motor neuron induction by vhh-1, a vertebrate homolog 
of hedgehog expressed by the notochord. Cell 76, 761-775 (1994).

12. Fietz, M. J. et al. The hedgehog gene family in Drosophila and vertebrate development. Dev. Suppl. 43-51 (1994).

13. Huangfu, D. et al. Hedgehog signalling in the mouse requires intraflagellar transport proteins. Nature 426, 83-87 (2003).

14. Goetz, S. C. \& Anderson, K. V. The primary cilium: a signalling centre during vertebrate development. Nat. Rev. Genet. 11, 331-344 (2010).

15. Nakano, Y. et al. A protein with several possible membrane-spanning domains encoded by the Drosophila segment polarity gene patched. Nature 341, 508-513 (1989).

16. Hooper, J. E. \& Scott, M. P. The Drosophila patched gene encodes a putative membrane protein required for segmental patterning. Cell 59, 751-765 (1989).

17. Marigo, V., Davey, R. A., Zuo, Y., Cunningham, J. M. \& Tabin, C. J. Biochemical evidence that patched is the Hedgehog receptor. Nature 384, 176-179 (1996).

18. Stone, D. M. et al. The tumour-suppressor gene patched encodes a candidate receptor for Sonic hedgehog. Nature 384, 129-134 (1996).

19. Fuse, N. et al. Sonic hedgehog protein signals not as a hydrolytic enzyme but as an apparent ligand for patched. Proc. Natl. Acad. Sci. U.S.A. 96, 10992-10999 (1999).

20. Rohatgi, R., Milenkovic, L. \& Scott, M. P. Patched1 regulates hedgehog signaling at the primary cilium. Science 317, 372-376 (2007).

21. Myers, B. R., Neahring, L., Zhang, Y., Roberts, K. J. \& Beachy, P. A. Rapid, direct activity assays for Smoothened reveal Hedgehog pathway regulation by membrane cholesterol and extracellular sodium. Proc Natl Acad Sci USA 114, E11141-E11150 (2017). 
22. Corbit, K. C. et al. Vertebrate Smoothened functions at the primary cilium. Nature 437, 1018-1021 (2005).

23. Préat, T. Characterization of Suppressor of fused, a complete suppressor of the fused segment polarity gene of Drosophila melanogaster. Genetics 132, 725-736 (1992).

24. Vokes, S. A., Ji, H., Wong, W. H. \& McMahon, A. P. A genome-scale analysis of the cisregulatory circuitry underlying sonic hedgehog-mediated patterning of the mammalian limb. Genes Dev. 22, 2651-2663 (2008).

25. Vokes, S. A. et al. Genomic characterization of Gli-activator targets in sonic hedgehogmediated neural patterning. Development 134, 1977-1989 (2007).

26. Biehs, B., Kechris, K., Liu, S. \& Kornberg, T. B. Hedgehog targets in the Drosophila embryo and the mechanisms that generate tissue-specific outputs of Hedgehog signaling. Development 137, 3887-3898 (2010).

27. Dai, P. et al. Sonic Hedgehog-induced activation of the Gli1 promoter is mediated by GLI3. J. Biol. Chem. 274, 8143-8152 (1999).

28. Ågren, M., Kogerman, P., Kleman, M. I., Wessling, M. \& Toftgård, R. Expression of the PTCH1 tumor suppressor gene is regulated by alternative promoters and a single functional Gli-binding site. Gene 330, 101-114 (2004).

29. Guy, R. K. Inhibition of sonic hedgehog autoprocessing in cultured mammalian cells by sterol deprivation. Proc. Natl. Acad. Sci. U.S.A. 97, 7307-7312 (2000).

30. Maity, T., Fuse, N. \& Beachy, P. A. Molecular mechanisms of Sonic hedgehog mutant effects in holoprosencephaly. Proc. Natl. Acad. Sci. U.S.A. 102, 17026-17031 (2005).

31. Cooper, M. K. et al. A defective response to Hedgehog signaling in disorders of cholesterol biosynthesis. Nat. Genet. 33, 508-513 (2003). 
32. Chevy, F., Illien, F., Wolf, C. \& Roux, C. Limb malformations of rat fetuses exposed to a distal inhibitor of cholesterol biosynthesis. Journal of Lipid Research 43, 1192-1200 (2002).

33. Cooper, M. K., Porter, J. A., Young, K. E. \& Beachy, P. A. Teratogen-mediated inhibition of target tissue response to Shh signaling. Science 280, 1603-1607 (1998).

34. Gofflot, F. Molecular mechanisms underlying limb anomalies associated with cholesterol deficiency during gestation: implications of Hedgehog signaling. Hum. Mol. Genet. 12, 1187-1198 (2003).

35. Stottmann, R. W. et al. Cholesterol metabolism is required for intracellular hedgehog signal transduction in vivo. PLoS Genet. 7, e1002224 (2011).

36. Matsui, T. et al. Canopy1, a positive feedback regulator of FGF signaling, controls progenitor cell clustering during Kupffer's vesicle organogenesis. PNAS 108, 9881-9886 (2011).

37. Okabe, N., Xu, B. \& Burdine, R. D. Fluid dynamics in zebrafish Kupffer's vesicle. Dev. Dyn. 237, 3602-3612 (2008).

38. Zhang, X. M., Ramalho-Santos, M. \& McMahon, A. P. Smoothened mutants reveal redundant roles for Shh and Ihh signaling including regulation of L/R symmetry by the mouse node. Cell 106, 781-792 (2001).

39. Hirate, Y. \& Okamoto, H. Canopy1, a Novel Regulator of FGF Signaling around the Midbrain-Hindbrain Boundary in Zebrafish. Current Biology 16, 421-427 (2006).

40. Hong, F. et al. CNPY2 is a key initiator of the PERK-CHOP pathway of the unfolded protein response. Nat. Struct. Mol. Biol. (2017).doi:10.1038/nsmb.3458

41. Mutoh, H. et al. Biallelic Variants in CNPY3, Encoding an Endoplasmic Reticulum 
Chaperone, Cause Early-Onset Epileptic Encephalopathy. The American Journal of

Human Genetics 102, 321-329 (2018).

42. Johnston, J. J. et al. Molecular analysis expands the spectrum of phenotypes associated with GLI3 mutations. Hum. Mutat. 31, 1142-1154 (2010).

43. Démurger, F. et al. New insights into genotype-phenotype correlation for GLI3 mutations. 23, 92-102 (2014).

44. Fogel, J. L., Lakeland, D. L., Mah, I. K. \& Mariani, F. V. A minimally sufficient model for rib proximal-distal patterning based on genetic analysis and agent-based simulations. eLIFE 6, (2017).

45. Dessaud, E., McMahon, A. P. \& Briscoe, J. Pattern formation in the vertebrate neural tube: a sonic hedgehog morphogen-regulated transcriptional network. Development 135, 2489-2503 (2008).

46. Lettice, L. A. \& Hill, R. E. Preaxial polydactyly: a model for defective long-range regulation in congenital abnormalities. Curr. Opin. Genet. Dev. 15, 294-300 (2005).

47. VanderMeer, J. E. \& Ahituv, N. cis-regulatory mutations are a genetic cause of human limb malformations. Dev. Dyn. 240, 920-930 (2011).

48. Al-Qattan, M. M. Zone of Polarizing Activity Regulatory Sequence Mutations/Duplications with Preaxial Polydactyly and Longitudinal Preaxial Ray Deficiency in the Phenotype: A Review of Human Cases, Animal Models, and Insights Regarding the Pathogenesis. Biomed Res Int 2018, 1573871 (2018).

49. Wheway, G., Nazlamova, L. \& Hancock, J. T. Signaling through the Primary Cilium. Front. Cell Dev. Biol. 6, 1358 (2018).

50. Reiter, J. F. \& Leroux, M. R. Genes and molecular pathways underpinning ciliopathies. 
Nature Reviews Molecular Cell Biology 18, 533-547 (2017).

51. Kim, J. et al. The role of ciliary trafficking in Hedgehog receptor signaling. Sci Signal 8, ra55 (2015).

52. Findakly, S. et al. Sterol and oxysterol synthases near the ciliary base activate the Hedgehog pathway. J Cell Biol 220, 1019 (2020).

53. Varjosalo, M., Li, S.-P. \& Taipale, J. Divergence of Hedgehog Signal Transduction Mechanism between Drosophila and Mammals. Dev. Cell 10, 177-186 (2006).

54. Raleigh, D. R. et al. Cilia-Associated Oxysterols Activate Smoothened. Mol. Cell 72, 316-327.e5 (2018).

55. Luchetti, G. et al. Cholesterol activates the G-protein coupled receptor Smoothened to promote Hedgehog signaling. eLIFE 5, (2016).

56. Huang, P. et al. Structural Basis of Smoothened Activation in Hedgehog Signaling. Cell 174, 312-324.e16 (2018).

57. Bruhn, H. A short guided tour through functional and structural features of saposin-like proteins. Biochem. J. 389, 249-257 (2005).

58. Munford, R. S., Sheppard, P. O. \& O'Hara, P. J. Saposin-like proteins (SAPLIP) carry out diverse functions on a common backbone structure. Journal of Lipid Research 36, 16531663 (2002).

59. Ahn, V. E., Faull, K. F., Whitelegge, J. P., Fluharty, A. L. \& Privé, G. G. Crystal structure of saposin B reveals a dimeric shell for lipid binding. PNAS 100, 38-43 (2002).

60. Ahn, V. E., Leyko, P., Alattia, J.-R., Chen, L. \& Privé, G. G. Crystal structures of saposins A and C. Protein Sci. 15, 1849-1857 (2006).

61. Rossmann, M. et al. Crystal Structures of Human Saposins C and D: Implications for 
Lipid Recognition and Membrane Interactions. Structure 16, 809-817 (2008).

62. Das, A., Brown, M. S., Anderson, D. D., Goldstein, J. L. \& Radhakrishnan, A. Three pools of plasma membrane cholesterol and their relation to cholesterol homeostasis. eLIFE 3, 19316 (2014).

63. Qi, X., Friedberg, L., Bose-Boyd, R., Long, T. \& Li, X. Sterols in an intramolecular channel of Smoothened mediate Hedgehog signaling. Nat. Chem. Biol. 1-21 (2020).doi:10.1038/s41589-020-0646-2

64. Huang, P. et al. Cellular Cholesterol Directly Activates Smoothened in Hedgehog Signaling. Cell 166, 1176-1187.e14 (2016).

65. Qi, X. et al. Cryo-EM structure of oxysterol-bound human Smoothened coupled to a heterotrimeric Gi. Nature (2019).doi:10.1038/s41586-019-1286-0

66. Rudolf, A. F. et al. The morphogen Sonic hedgehog inhibits its receptor Patched by a pincer grasp mechanism. Nat. Chem. Biol. 1-14 (2019).doi:10.1038/s41589-019-0370-y

67. Radhakrishnan, A., Rohatgi, R. \& Siebold, C. Cholesterol access in cellular membranes controls Hedgehog signaling. Nat. Chem. Biol. 1-11 (2020).doi:10.1038/s41589-02000678-2

68. Milenkovic, L. et al. Single-molecule imaging of Hedgehog pathway protein Smoothened in primary cilia reveals binding events regulated by Patched1. Proc Natl Acad Sci USA 112, 8320-8325 (2015).

69. Weiss, L. E., Milenkovic, L., Yoon, J., Stearns, T. \& Moerner, W. E. Motional dynamics of single Patched1 molecules in cilia are controlled by Hedgehog and cholesterol. Proc Natl Acad Sci USA 116, 5550-5557 (2019).

70. Fagone, P. \& Jackowski, S. Membrane phospholipid synthesis and endoplasmic reticulum 
function. Journal of Lipid Research 50, S311-S316 (2009).

71. Jacquemyn, J., Cascalho, A. \& Goodchild, R. E. The ins and outs of endoplasmic reticulum $\square$ controlled lipid biosynthesis. EMBO Rep 18, 1905-1921 (2017).

72. Konno, K. et al. A molecule that is associated with Toll-like receptor 4 and regulates its cell surface expression. Biochemical and Biophysical Research Communications 339, 1076-1082 (2006).

73. Hart, B. E. \& Tapping, R. I. Cell Surface Trafficking of TLR1 Is Differentially Regulated by the Chaperones PRAT4A and PRAT4B. J. Biol. Chem. 287, 16550-16562 (2012).

74. Metscher, B. D. MicroCT for comparative morphology: simple staining methods allow high-contrast 3D imaging of diverse non-mineralized animal tissues. BMC Physiol 9, 11 (2009). 


\section{FIGURE LEGENDS}

Fig. 1 | Developmental defects in Cnpy $^{-/-}$hindlimbs. a, Single-molecule in situ hybridization (RNAscope) of Cnpy4 in hindlimbs of wild-type and Cnpy4 mutant embryos at E12.5. Boxed areas are magnified on the bottom. b, Protein extracts of MEFs from control and mutant embryos were blotted with an anti-CNPY4 antibody and an $\beta$-tubulin loading control antibody. c, Dorsal view of wild-type and Cnpy4 mutant limbs at E18.5 (top row) and E14.5 (middle row). The majority of Cnpy4 hindlimbs exhibit either an extra digit anteriorly (yellow asterisk) or a transformation of digit 1 from biphalangeal to triphalangeal (red asterisk). The top table summarizes the phenotype frequency in mutant hindlimbs; less frequent phenotypes are shown in Extended Figure 1a, b Whole mount in situ hybridization for Sox9 (bottom row) indicates an extra digit (arrow) and an enlarged digit 1 primordium.

\section{Fig. 2 | Absence of Cnpy4 leads to hyperactivation of HH-related gene expression and}

signaling. a, In situ hybridization and lacZ expression of Shh and Glil-lacZ in hindlimb buds at E10.5, E11.5 and E12.5 showing enlarged Shh domain (circles and lines) and ectopic expression of both Shh and Gli1 (arrrowheads) in the Cnpy4 mutants. b, c, Luciferase reporter assay in ciliated NIH3T3 cells treated with Cnpy4 or control siRNA and stimulated with SAG or recombinant SHH (b) and 20(S)-hydroxycholesterol or 24(S), 25-epoxycholesterol (c). Quantifications were normalized to the average value of control siRNA treated cells stimulated with DMSO or vehicle. d, e, qRT-PCR assessment of Glil expression in ciliated NIH3T3 cells treated with Cnpy4 or control siRNA and stimulated with SAG or recombinant SHH (d) and 20(S)-hydroxycholesterol or 24(S), 25-epoxycholesterol (e). Significance calculations were performed as described in Methods and Materials; **** $\mathrm{p}<0.0001$ 
Fig. 3 CNPY4 intersects the HH pathway at the level of SMO. a, Immunofluorescence of primary cilia (acetylated tubulin, red), SMO (SMO, green), and nuclei (DAPI, blue) in ciliated NIH3T3 cells treated with Cnpy4 or control siRNA. The scale bar represents $10 \mathrm{um}$. Inset scale bar represents 1 um. b, Quantification of number of NIH3T3 cells ciliated as assessed by acetylated tubulin immunofluorescence. c, Quantification of ciliary length in NIH3T3 cells. Measurements were performed in FIJI using the acetylated tubulin channel. d-g, Luciferase reporter assay in ciliated Ptchl (d), Sufu (e), or Smo (f, g) null MEFs treated with Cnpy4 or control siRNA, with Smo null MEFs stimulated with either SAG (f) or SHH (g). Quantifications were normalized to the average value of control siRNA treated cells. $\mathbf{h}, \mathbf{i}$, Luciferase reporter assay in ciliated NIH3T3 cells treated with Cnpy4 or control siRNA stimulated with SAG (h) or SHH (i) in the presence of SANT-1. Quantifications were normalized to the average value of control siRNA treated cells stimulated with DMSO. All significance calculations were performed as described in Methods and Materials; ** $\mathrm{p}<0.005, * * * * \mathrm{p}<0.0001$

Fig. 4 | CNPY4 modulates levels of accessible cholesterol. a, Immunofluorescence of accessible cholesterol (PFO*-AF647, red) and nuclei (DAPI, blue) of NIH3T3 cells treated with Cnpy4 or control siRNA. Boxed areas are magnified on the right. b, c, FACS analysis of NIH3T3 treated with Cnpy4 or control siRNA (b) or Cnpy $4^{+/+}$and $C n p y 4^{-/-}$MEFs (c) stained with PFO*-AF647 for accessible cholesterol. Quantifications were normalized to the average value of control siRNA treated cells. Significance calculations were performed as described in Methods and Materials; $* * * * \mathrm{p}<0.0001$. d, Schematic illustrating CNPY4 modulation of HH activation. CNPY4, an ER-resident protein, likely modulates the ability of sterols, synthesized in 
the ER, to traffic to the ciliary membrane, thus modulating the ability of SMO to become activated in a manner parallel to that of PTCH1 regulation of SMO. In the absence of CNPY4, PTCH1 inhibition of SMO is bypassed by the elevated levels of membrane sterols, which lead to hyperactivation of $\mathrm{HH}$ signaling through SMO. 
bioRxiv preprint doi: https://doi.org/10.1101/2021.03.15.435490; this version posted March 16, 2021. The copyright holder for this preprint Fig (uterhiwals ootededied by peer review) is the author/funder, who has granted bioRxiv a license to display the preprint in perpetuity. It is made available under aCC-BY-NC-ND 4.0 International license.

a

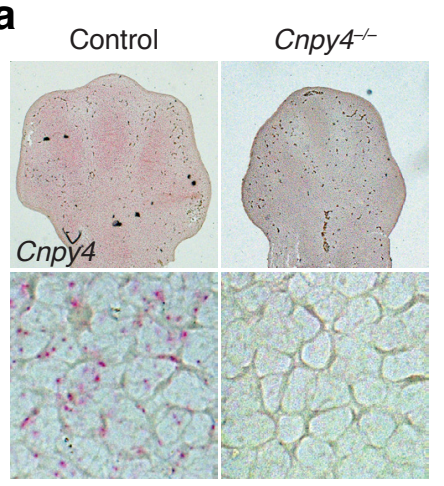

b

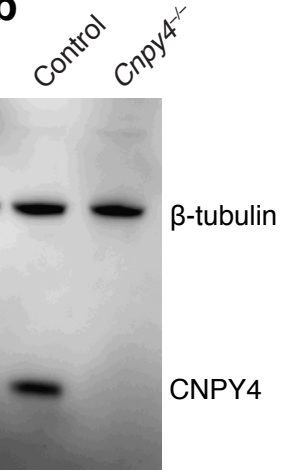

C

$$
\begin{aligned}
& \text { Preaxial } \\
& \text { polydactyly }
\end{aligned}
$$

Posterization

Wild

(6 digits) (5 digits)

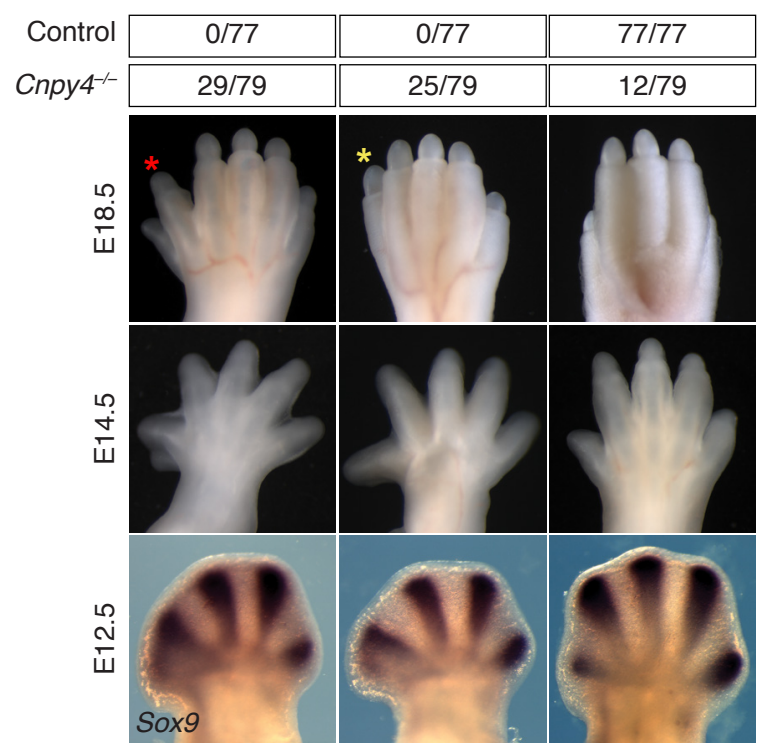


a Shh Gli1-LacZ
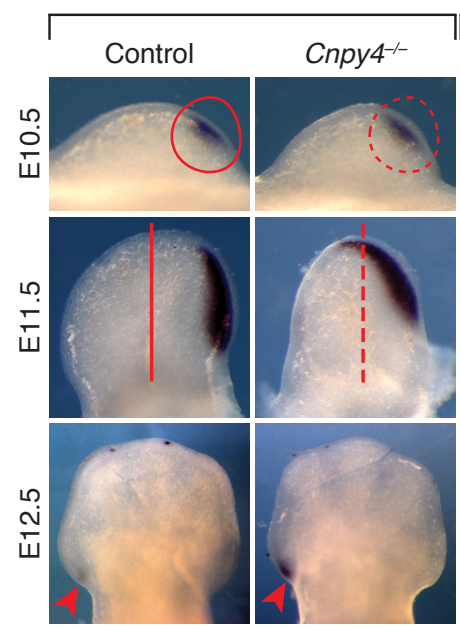

Control Cnpy4 ${ }^{-/}$
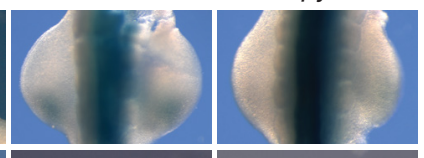

b
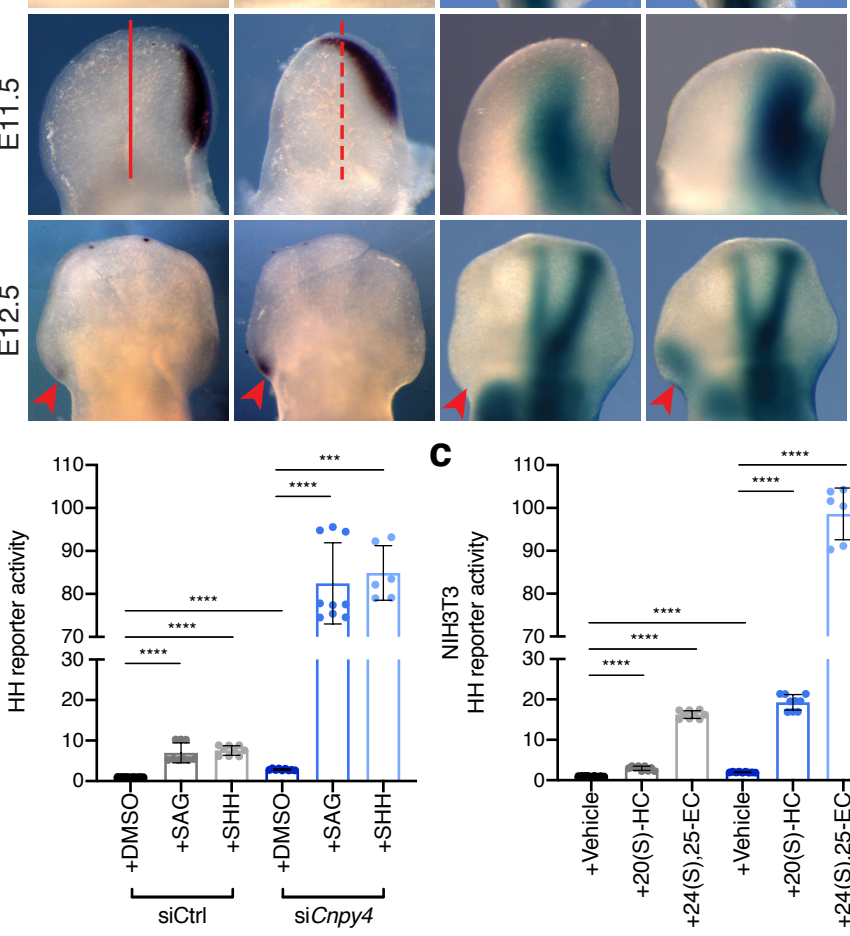

c
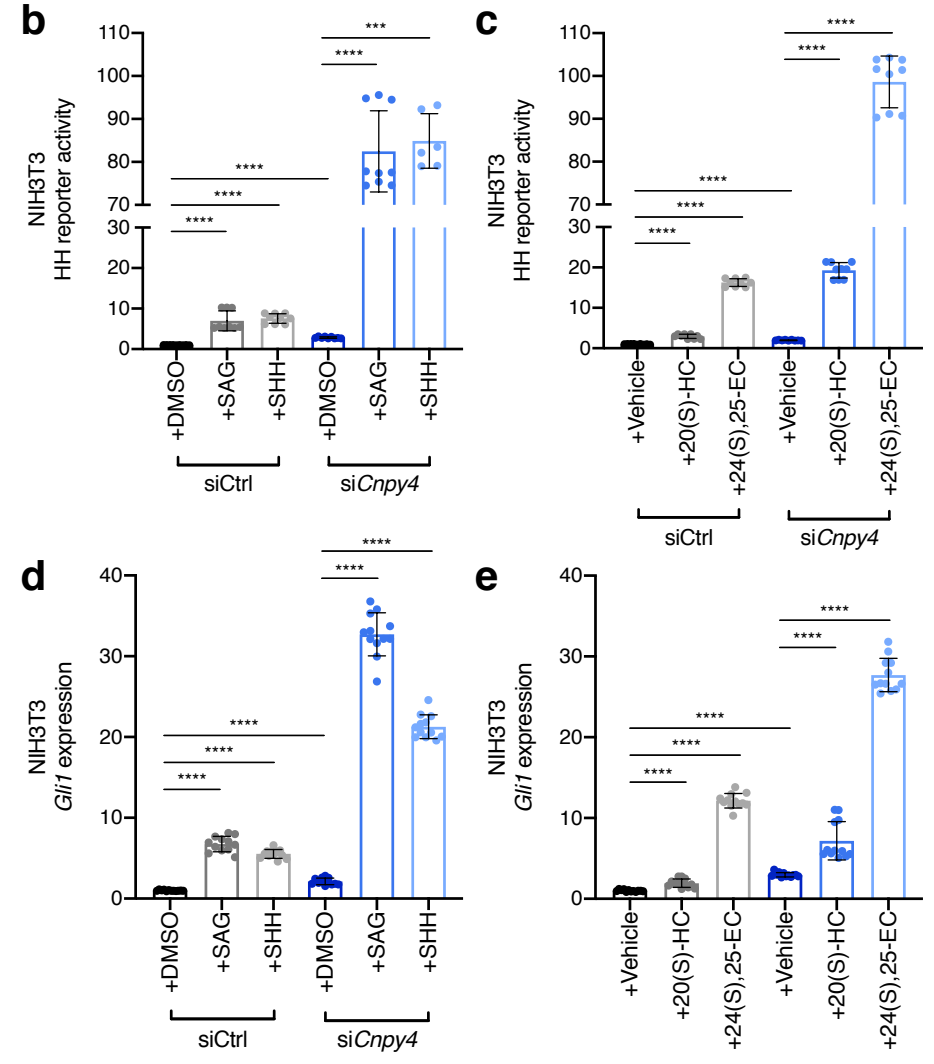

e

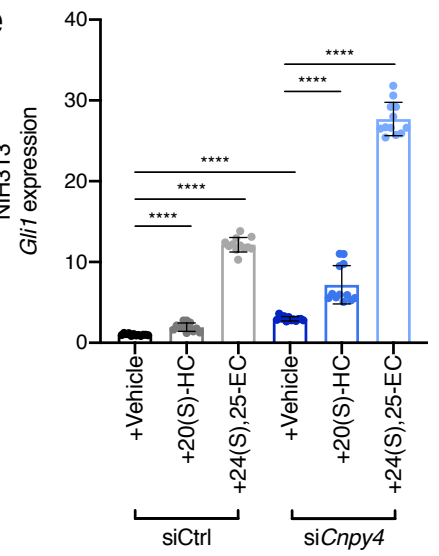



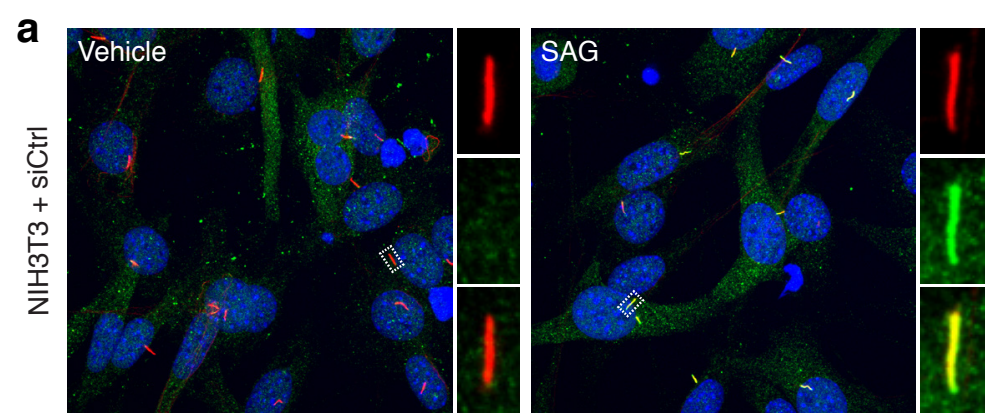

\section{b}
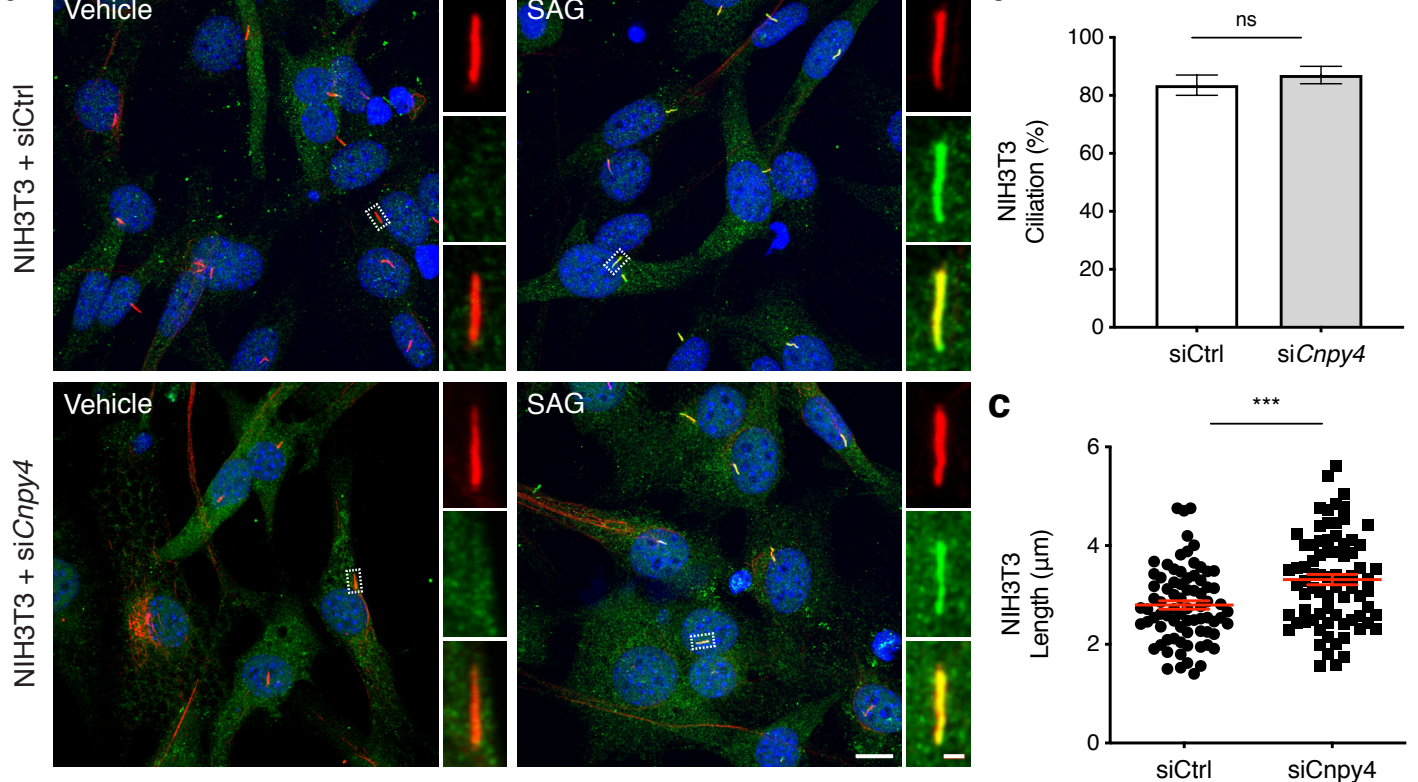

AcTub

DAPI
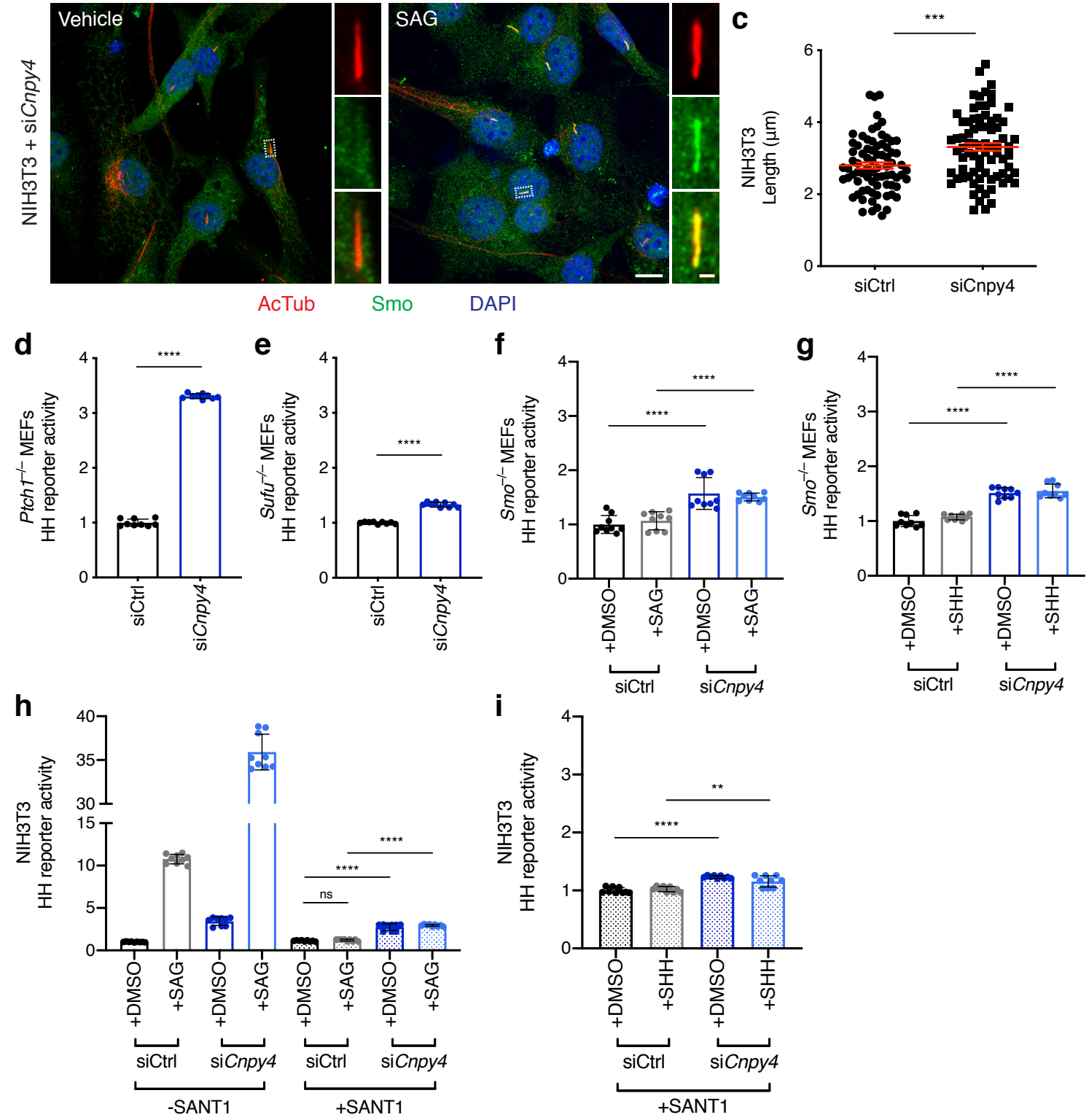
bioRxiv preprint doi: https://doi.org/10.1101/2021.03.15.435490; this version posted March 16, 2021. The copyright holder for this preprint

Fig(urerifyalsooteded by peer review) is the author/funder, who has granted bioRxiv a license to display the preprint in perpetuity. It is made available under aCC-BY-NC-ND 4.0 International license.
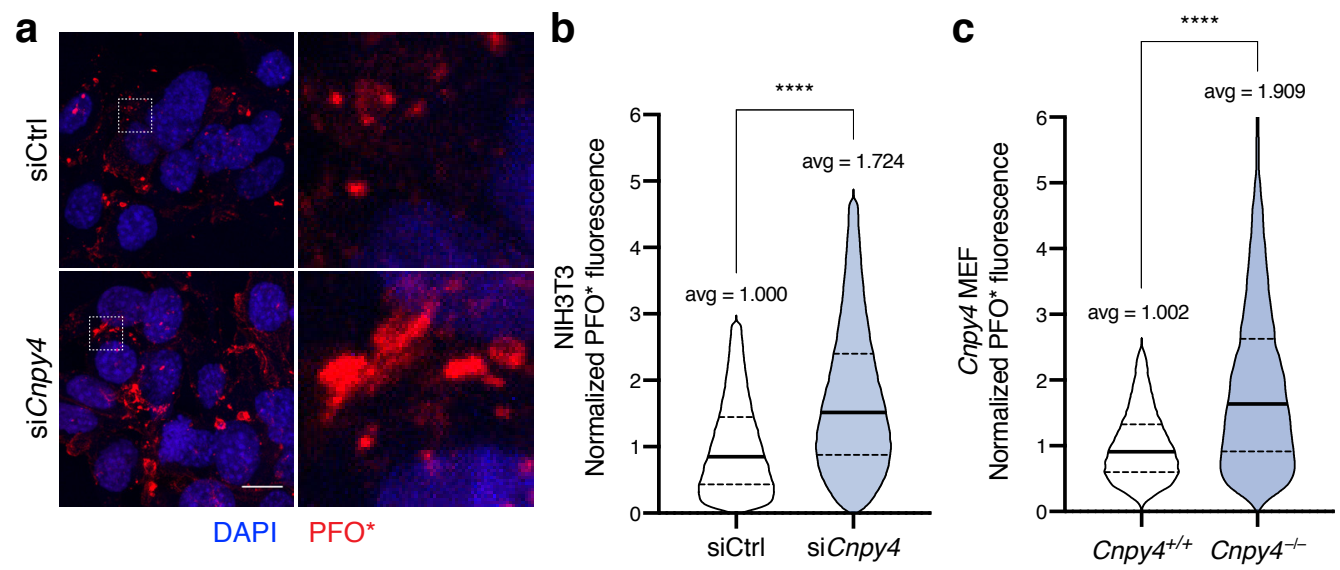

d

PTCH1-dependent

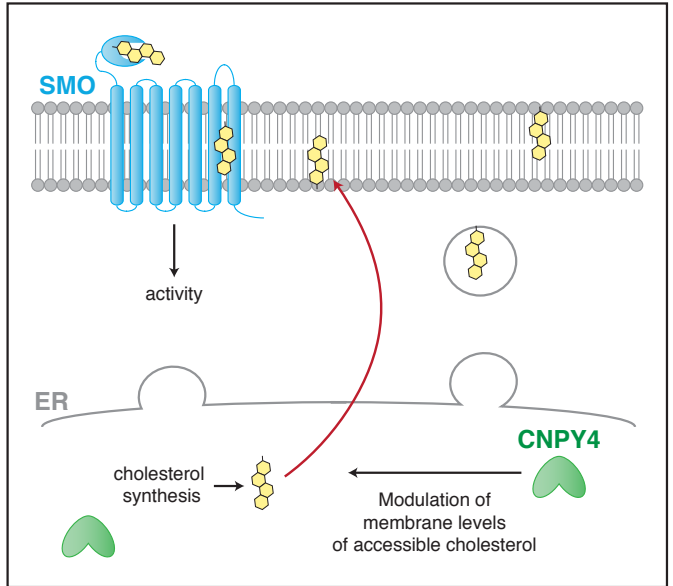

PTCH1-independent

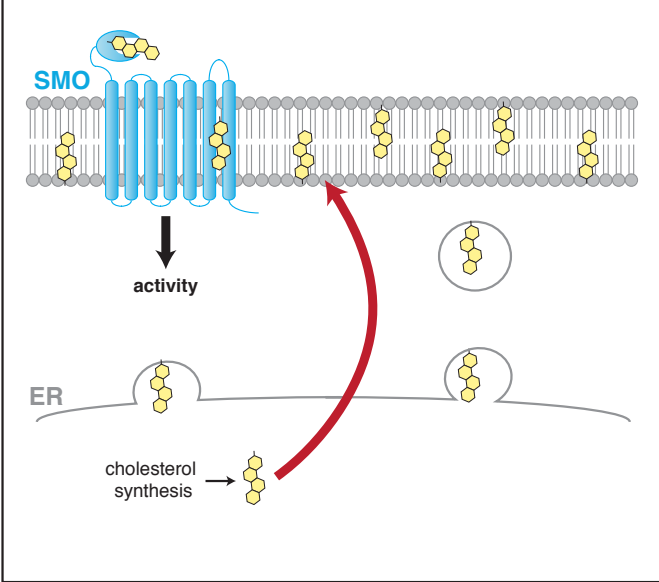

